\title{
THE UNIVERSITY, DRIVER OF INNOVATION
}

Juan Antonio Raga

Several universities have recently made the front page of newspapers, televisions, and other media, but, unfortunately, the reason behind this was not their day-to-day work, focused on training and research, but some cases of malpractice by certain academics who used and abused the institution for personal gain.

By its very nature as a public service, the University is based on analysis and criticism, including self-criticism. Very few institutions are. Perhaps that is why, without ignoring the fact that there is room for improvement, we must prove

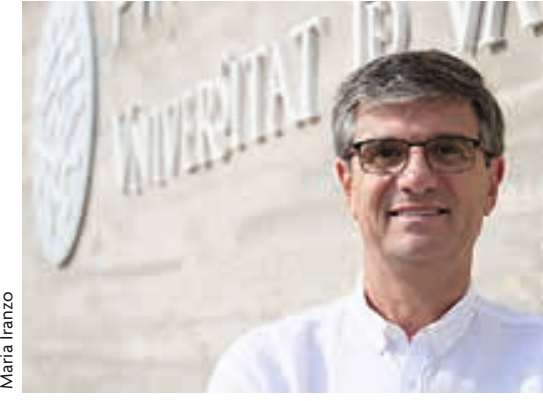

«WE MUST PROVE THE INCREASINGLY IMPORTANT ROLE THAT UNIVERSITIES HAVE BEEN GIVEN, AS WELL AS THEIR ACHIEVEMENTS" the Spanish National Research Council) and, for the first time, knowledge-based companies are being regarded in their own right. A total of 200 companies have flourished in the Science and Technology Park in almost a decade. Some have disappeared due to market difficulties and the economic crisis, but others have grown so much that they have continued their development and internationalisation in other places, responding to new space needs or to a level of consolidation that makes them independent of the University's commitment to entrepreneurship.

The Science and Technology

Park currently hosts 85 innovative companies with an annual turnover of over 30 million euros. These companies have generated 470 direct jobs close to gender equality ( $43 \%$ of women and $57 \%$ of men), and where graduates represent $83.7 \%$ ( $15 \%$ of whom hold PhDs). These figures show that the institutional commitment made it possible to generate an active innovative ecosystem that, in under ten years, has made a positive impact on our environment.

We live in an age of dizzying novelties, where new technologies in robotics, ICT, big data, biotechnology, or materials - all of which are areas of activity that are present at the PCUV - will achieve breakthroughs that were previously unimaginable. Therefore, twenty-first-century universities must participate in these challenges that will eventually lead to a new and sustainable economic model and contribute to solving the problems that those new circumstances will create in society. Universities, generators of knowledge and innovation, must be restless and sensitive to change, ready to face new challenges and help societies improve and move forward.

Juan Antonio Raga. Full Professor of Zoology and Director of the Science and Technology Park of the University of Valencia. 